JSACE $2 / 23$

\section{Comparison Between Modular Building Technology and Traditional \\ Construction}

Received

2018/08/24

Accepted after

revision

2018/11/05

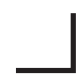

\section{Introduction}

\section{ktu}

Journal of Sustainable Architecture and Civil Engineering Vol. 2 / No. 23 / 2018 pp. $86-95$ DOI 10.5755/j01.sace.23.2.21579

\section{Comparison Between Modular Building Technology and Traditional Construction}

\author{
Julius Endzelis*, Mindaugas Daukšys \\ Kaunas University of Technology, Faculty of Civil Engineering and Architecture \\ Studentu str. 48, LT-51367 Kaunas, Lithuania \\ *Corresponding author: julius.endzelis@gmail.com \\ $\Gamma$ \\ crossef $h t t p: / / d x . d o i . o r g / 10.5755 / j 01 . s a c e .23 .2 .21579$
}

This article presents a comparison of modular construction technology with traditional construction based on the results of the survey. The aim of the survey was to find out experts opinion about modular construction, the innovative way of building and its advantages and disadvantages compared to traditional building method. The results of the survey showed that modular construction has more pros than cons compared with the traditional construction method and is more economical and saves more time and materials. The most important criteria that demonstrates the clear advantage of modular construction technology is the duration of construction, the quality of work performed, and the safety of work. This research is based on master thesis topic.

Keywords: modular construction, metal frame module, wooden frame module, traditional construction.

Modern building technologies are so advanced that simply just by choosing the structure of a building it will be built in a few days or weeks. The construction time has been significantly shortened, construction has become more sustainable. Modular construction technology (3D Volumetric Construction) is one such construction technology. Every year, both investors and ordinary consumers are showing increasing interest in modular homes and it is quickly becoming the new way in home building comparing to the traditional construction. This type of construction has a lot of advantages against traditional construction, such as shorter construction time, higher quality and possibly saving some money. More and more clients want a multi-storey health care or educational institutions made out of modules. In the Lithuanian market, the main companies involved in the production of modules are JSC „Scandi House“, JSC „Ryterna“, JSC „Kagesa“, JSC „Wilbergs Group“.

Modular construction is a process in which several modules of the same house are manufactured at the factory, and at the same time construction site and foundation work is being carried out. The publication (Modular Building Institute, 2010) present the factors that have the greatest impact on the productivity of the construction industry. One of these factors is the modular construction, which reduces the cost of the project, shortens the work schedules, improves the quality of the building and reduces the need for workers and material cost on the construction site. The authors (Jellen and Memari 2013) describe the types of modular homes, their construction advantages, applications and challenges in the modular home sector. Smith (2016) describes non-site generated modules, their benefits, and when it's best to use them instead of traditional construction. Generalova et al (2016) discusses the temporary use of modular elements in construction. 
It is emphasized that modular structures can shorten the duration of a project, reduce costs and improve construction productivity. It is written about Russia's extensive experience in the development of reinforced concrete modules. It also describes perspectives and relevance not only at low elevations, but also in the construction of multi-storey and high-rise modular constructions. The authors (Shafari et al 2017) describes innovative, integrity-enhancing multi-storey building modular systems. Zhang et al (2016) looks at the history of industrialization in the Chinese construction industry and discusses the prospects for using BIM (Building Information Modelling) in modular and industrial construction. It discusses the use of advanced tools, including a 3D laser scanner to collect real-world information and to use robotized all-station (tacheometer) for quick installation. The authors (Lopez and Froese 2016) provide a detailed analysis of the cost of the two main categories of prefabricated houses - panel and modular. The main goal of the study is to provide information on the implications and compromises of both construction methods for construction of a single family home, as well as to determine which option is more cost-effective. Ding et al (2017) describes the quasi-static CSPSW (Corrugated Steel Plate Shear Wall) method for walls with and without openings to assess seismic influences on walls. Two different cases of side force countermeasures are discussed. Several design recommendations are also provided, which will be useful for using the CSPSW method in the seismic zone. The authors (Mohsen et al 2008) discuss in their work with the Simphony.NET application's ability to analyze design and construction work. The analysis was carried out both before and after project implementation, in order to predict the construction efficiency and duration, and to give access to alternative construction scenarios. The authors (Lee et al 2016) suggest optimizing the construction process at the factory stage using matrix of dependency structure, which takes into account the process approach based on construction information flow at work. Kamali and Hewage (2016) discusses the methodology used to identify and select appropriate Life Cycle Indicators (SPIs) that value sustainability in the construction of modular and traditional homes. The authors identified SPI indicators for assessing the life cycle of buildings. It also conducted a survey in its study to assess the application of sustainability indicators for comparing modular and traditional construction.

The authors (Molavi and Barral 2016) provide a simple explanation of modular and panel systems and propose construction project design methods based on project type to avoid various disadvantages in sustainable modular construction. The authors (Kamali and Hewage 2016) discuss the production of different types of modules for production at the plant and for their assembly on the construction site. It also describes the benefits of modules such as time, life expectancy, price and nature conservation. Matei (2017) writes about the next generation of "Ten fold" modules that do not need to install a foundation or hire a crane. Eagle (2014) writes about building a hospital using modules. The article also mentions the benefits of modular construction such as lower costs and time. Sevenson (2015) writes about a 3D-printed and built modular house that can withstand a magnitude 9.0 earthquake, based on the Richter scale. The authors (Ngo et al 2009) describe the work done by the metal frame modular house in order to determine whether this construction method is more environmentally friendly. The results are compared with the usual construction method. The authors (Larsson et al 2012) present a logical outline for an innovative architectural stacking methodology based on three Swedish timber construction systems and how much stories each system is capable of producing which is up to 20 stories. Aaron Morby (2017) writes that Tide Construction, with funding from investor Greystar, is planning to build modular building containing of two towers 44 and 38 storeys on former Essex House site near to East Croydon station, Greater London.

This work seeks to find out why in foreign countries the popular way of building is not promoted in the Lithuania, to review the advantages and disadvantages of modular construction and the main criteria that determine the choice of modular construction technology. 
Methods

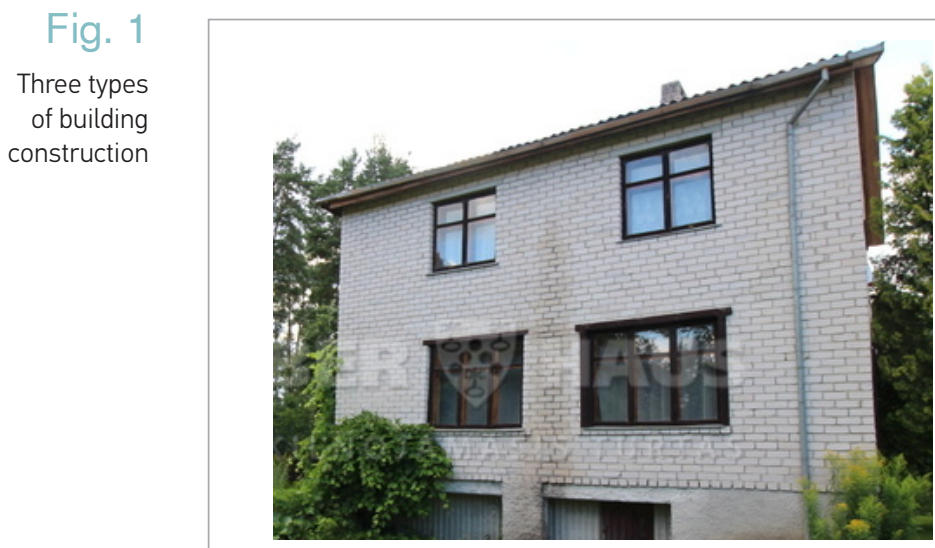

a) Calcium silicate bricks masonry building (www.ober-haus.lt)

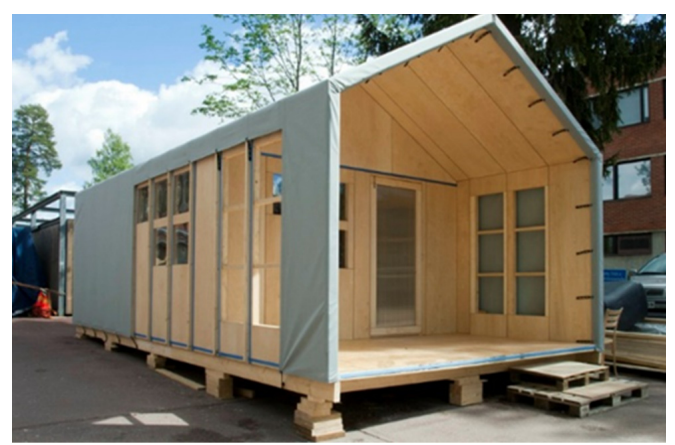

b) Wooden frame module building (https://inhabitat.com)

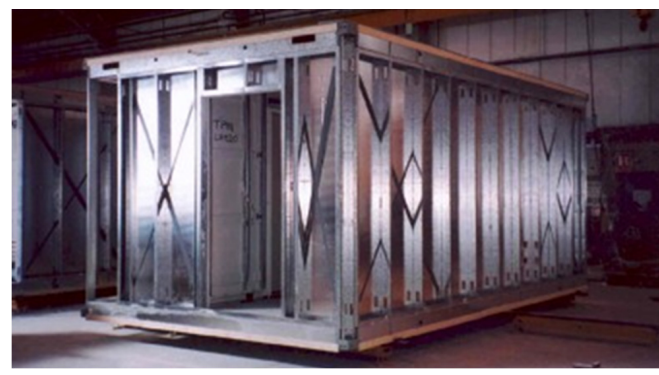

c) Metal frame module building (Lawson and Ogden, 2008)
Metal frame module - A3. The modules are made of metal frame and are designed for both low-rise and multi-storey buildings. The metal frame is designed to accommodate future loads. Frame elements can be interconnected by screw couplings or welded together. Example of metal frame module is given in Fig. 1c (Lawson and Ogden 2008).

During the study, the wall and roof parts of each of the 3 possible variants were designed to meet the requirements of thermal resistance $A++$ (Fig. 2). Following the design of the wall, using the Autodesk Revit software, 3 versions of the same 5 floor residential building were designed (modular wooden frame, modular metal frame and masonry building).

Outside dimensions of the building are $30.6 \times 13.5 \times 16.2 \mathrm{~m}$. All three versions of the residential building use Paroc mineral wool as a thermal insulation. The only difference between versions is that modular buildings have thermal insulation between framing (Fig. 3). Both modular versions of a building contain 24 units in one floor (120 units in total for a building). By designing all three options, the Autodesk Revit program counted the cost of materials for each option, and the SISTELA program counted the construction cost of each option construction. 


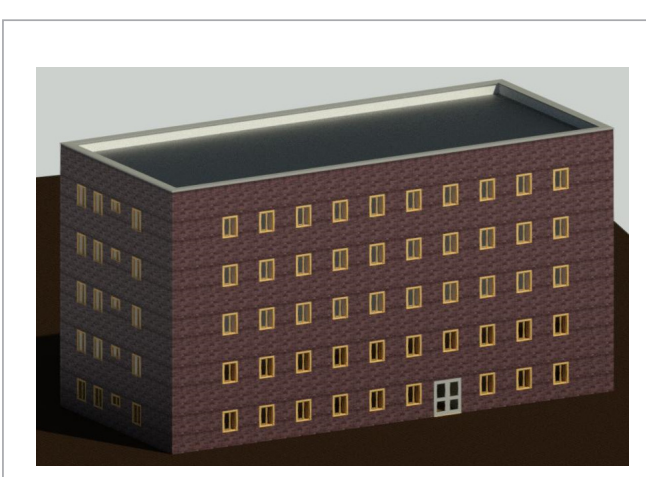

a) $3 \mathrm{D}$ view

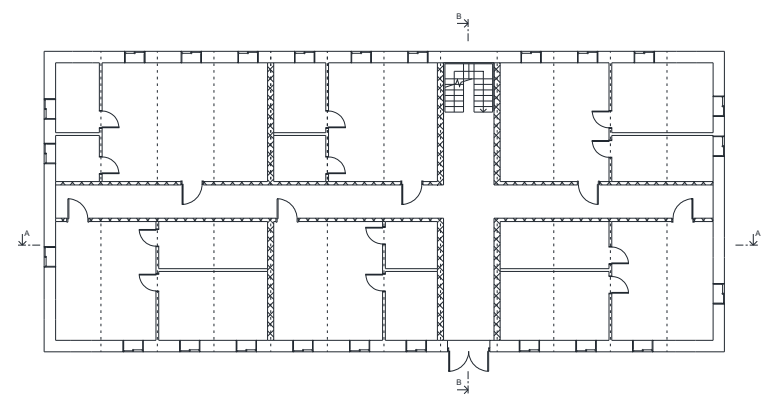

c) floor plan view

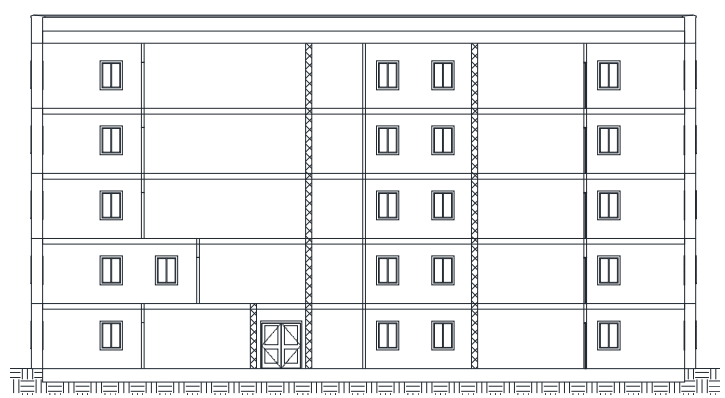

b) A-A cros-section view

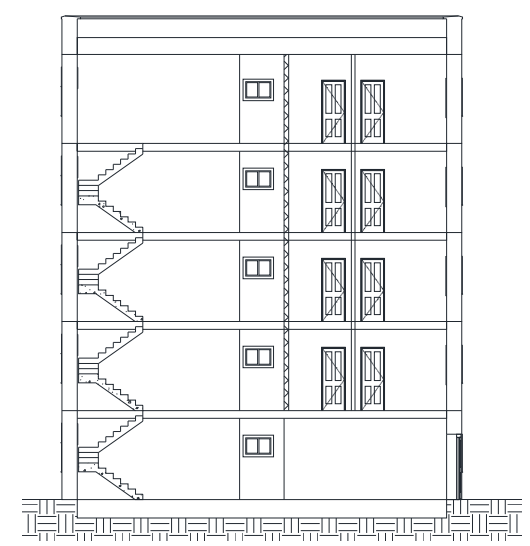

d) B-B cros-section view

After calculating the estimate of each possibility, it was possible to see the price of $1 \mathrm{~m}^{2}$ living space, the duration of work, the need of human resources and mechanisms. The following evaluation criteria were selected for measuring the comparison of selected type of building construction:

_ $\mathrm{K}_{1}-1 \mathrm{~m}^{2}$ installation cost, Eur $/ \mathrm{m}^{2}$;

_ $\mathrm{K}_{2}$ - construction time (work carried out consistently), work days;

_ $\mathrm{K}_{3}$ - work safety during construction work, points;

- $\mathrm{K}_{4}$ - environmental protection, points;

_ $\mathrm{K}_{5}$ - man-hours, $\mathrm{h} / \mathrm{m}^{2}, \mathrm{~h} / \mathrm{m}^{2}$;

- $\mathrm{K}_{6}$ - quality of work performed, points;

_ $\mathrm{K}_{7}$ - machine-hours, $\mathrm{h} / \mathrm{m}^{2}$.

Evaluation criteria for each type of building construction are different (Table 1).

The following multi-criteria evaluations were used to conduct the study:

- Expert multi-criteria assessment - this research method has allowed to identify the most important criteria using the survey;

- Theoretical multi-criteria assessment - this evaluation method has allowed to identify the most important criteria from the collected data;

- Complex multi-criteria assessment - this assessment method has allowed to identify the most important criteria using the results of expert and theoretical evaluation;

Multi-criterion utility method - this evaluation method has made it possible to determine which alternative is the rational option from the three analysed options. 
Fig. 3. Examples of structure system details of 3 versions of the same residential building

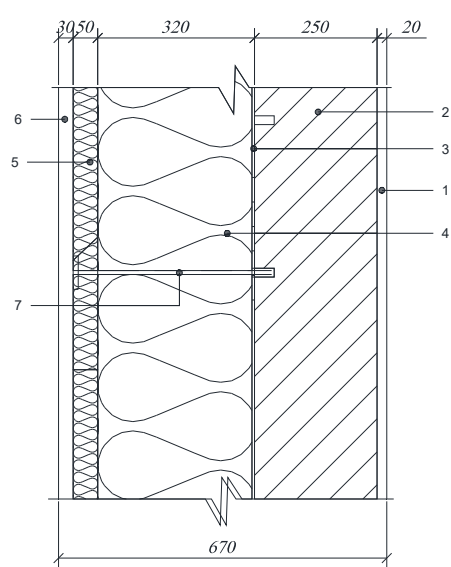

1. Gypsum plaster $\left(r=1300 \mathrm{kgm}^{3}\right)$ $\mathrm{d}=20 \mathrm{~mm}, \lambda=0.57 \mathrm{~W} / \mathrm{mK}$;

2. Ceramic blocks Keraterm 25 $\mathrm{d}=250 \mathrm{~mm}, \lambda=0.22 \mathrm{~W} / \mathrm{mK}$;

3. Tyvek Airguard Reflective;

4. PAROC eXtra plus $-d=320 \mathrm{~mm}$, $\lambda=0.036 \mathrm{~W} / \mathrm{mK}$

5. PAROC Cortex $-\mathrm{d}=50 \mathrm{~mm}$, $\lambda=0.033 \mathrm{~W} / \mathrm{mK}$;

6. Decorative plaster $-\mathrm{d}=30 \mathrm{~mm}$, $\lambda=0.8 \mathrm{~W} / \mathrm{mK}$

7. Insulation pin $-d=450 \mathrm{~mm}$;

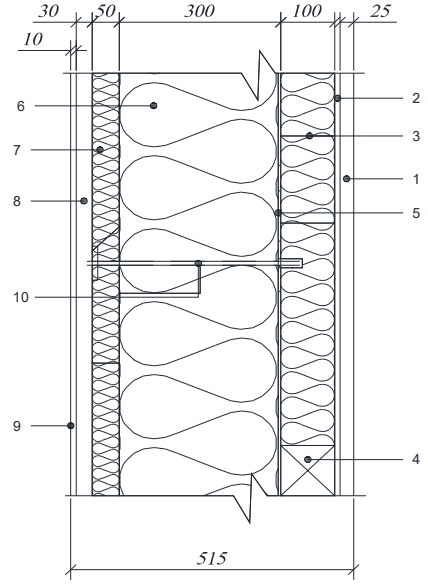

1. Gypsum boards $\left(r=1300 \mathrm{kgm}^{3}\right)-d=25 \mathrm{~mm}$, $\lambda=0.57 \mathrm{~W} / \mathrm{mK}$ :

2. Tyvek Airguard Reflective;

3. PAROC eXtra plus $-d=100 \mathrm{~mm}, \lambda=0.036 \mathrm{~W} /$ $\mathrm{mK}$;

4. Cross laminated timber $100 \times 100 \mathrm{~mm}$, every $1200 \mathrm{~mm}-\lambda=0.18 \mathrm{~W} / \mathrm{mK}$

5. OSB panel $-\mathrm{d}=10 \mathrm{~mm}, \lambda=0.13 \mathrm{~W} / \mathrm{mK}$;

6. PAROC eXtra plus $-\mathrm{d}=300 \mathrm{~mm}, \lambda=0.036 \mathrm{~W} / \mathrm{mK}$;

7. PAROC cortex $-d=50 \mathrm{~mm}, \lambda=0.033 \mathrm{~W} / \mathrm{mK}$;

8. Fully ventilated air gap / T profile $\mathrm{d}=30 \mathrm{~mm}$;

9. Façade panel Tectiva

10.Insulation pins $-d=400 \mathrm{~mm}$;

a) wall system details
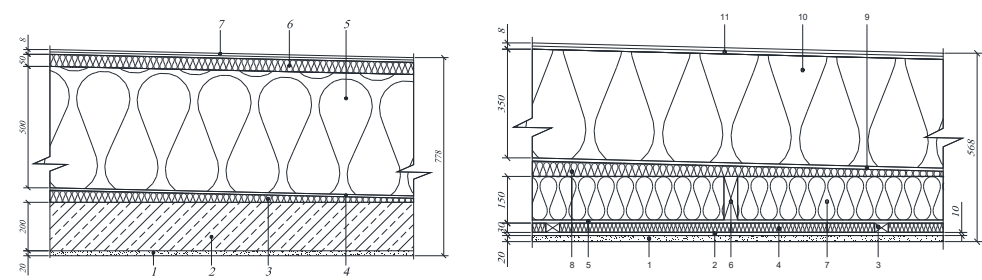

1. Gypsum plaster $-\mathrm{d}=20 \mathrm{~mm}$, $\lambda=0.57 \mathrm{~W} / \mathrm{mK}$;

2. Monolithic concrete $-\mathrm{d}=200 \mathrm{~mm}$, $\lambda=2.5 \mathrm{~W} / \mathrm{mK}$

3. Slope forming thermal insulation layer

4. Tyvek Airguard Reflective;

5. PAROC eXtra plus $-d=500 \mathrm{~mm}$, $\lambda=0,036 \mathrm{~W} / \mathrm{mK}$

6. PAROC cortex $-\mathrm{d}=50 \mathrm{~mm}$, $\lambda=0.033 \mathrm{~W} / \mathrm{mK}$

7. MIDA BIPOL $-\mathrm{d}=8 \mathrm{~mm}$, $\lambda=0.17 \mathrm{~W} / \mathrm{mK}$.

10. PAROC eXtra plus $-\mathrm{d}=350 \mathrm{~mm}, \lambda=0.036 \mathrm{~W} / \mathrm{mK}$;

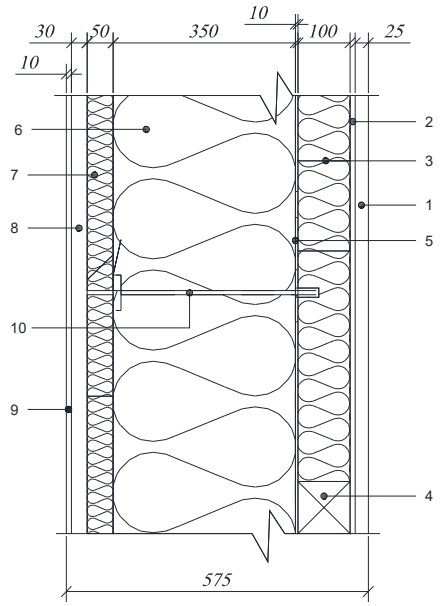

1. Gypsum board $\left(r=1300 \mathrm{kgm}^{3}\right)-d=25 \mathrm{~mm}$, $\lambda=0.57 \mathrm{~W} / \mathrm{mK}$

2. Tyvek Airguard Reflective;

3. PAROC eXtra plus $-d=100 \mathrm{~mm}, \lambda=0.036 \mathrm{~W} /$ $\mathrm{mK}$;

4. Square metal profile $100 \times 100 \mathrm{~mm}$, every $2000 \mathrm{~mm}-\lambda=50 \mathrm{~W} / \mathrm{mK}$

5. OSB panel $-d=10 \mathrm{~mm}, \lambda=0.13 \mathrm{~W} / \mathrm{mK}$;

6. PAROC eXtra plus $-\mathrm{d}=350 \mathrm{~mm}, \lambda=0.036 \mathrm{~W} / \mathrm{mK}$;

7. PAROC cortex $-\mathrm{d}=50 \mathrm{~mm}, \lambda=0.033 \mathrm{~W} / \mathrm{mK}$;

8. Fully ventilated air gap / T profile $\mathrm{d}=30 \mathrm{~mm}$;

9. Fasadinè plokštè Tectiva

10. Insulation pins $-d=450 \mathrm{~mm}$;

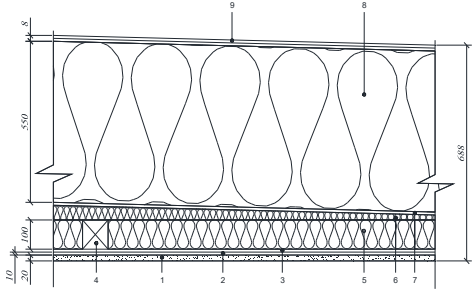

1. Gypsum plaster $-\mathrm{d}=20 \mathrm{~mm}, \lambda=0.57 \mathrm{~W} / \mathrm{mK}$;

2. OSB panel $-\mathrm{d}=10 \mathrm{~mm}, \lambda=0.13 \mathrm{~W} / \mathrm{mK}$;

3. Tyvek Airguard Reflective;

4. Square metal profile $100 \times 100 \mathrm{~mm}$, every $2000 \mathrm{~mm}-\lambda=50 \mathrm{~W} / \mathrm{mK}$;

5. PAROC eXtra plus $-\mathrm{d}=100 \mathrm{~mm}, \lambda=0,036 \mathrm{~W} /$ $\mathrm{mK}$;

6. Slope forming thermal insulation layer

7. Tyvek Housewrap

8. PAROC eXtra plus $-\mathrm{d}=550 \mathrm{~mm}, \lambda=0.033 \mathrm{~W} /$ $\mathrm{mK}$;

9. $\mathrm{MIDA}$ BIPOL $-\mathrm{d}=8 \mathrm{~mm}, \lambda=0.17 \mathrm{~W} / \mathrm{mK}$;

11. MIDA BIPOL $-\mathrm{d}=8 \mathrm{~mm}, \lambda=0.17 \mathrm{~W} / \mathrm{mK}$;

b) roof system details 


\begin{tabular}{|c|c|c|c|}
\hline Type of building construction & $\begin{array}{c}\text { Calcium silicate bricks } \\
\text { masonry building }\end{array}$ & $\begin{array}{l}\text { Wooden frame } \\
\text { module }\end{array}$ & $\begin{array}{l}\text { Metal frame } \\
\text { module }\end{array}$ \\
\hline $1 \mathrm{~m}^{2}$ installation cost, Eur $/ \mathrm{m}^{2}$ & 734.77 & 704.74 & 679.28 \\
\hline Construction time, work days; & 210 & 126 & 126 \\
\hline Work safety during construction work, points & 5 & 8 & 8 \\
\hline Environmental protection, points & 5 & 8 & 8 \\
\hline Man-hours, $\mathrm{h} / \mathrm{m}^{2}, \mathrm{~h} / \mathrm{m}^{2}$ & 9.8 & 5.2 & 5.4 \\
\hline Quality of work performed, points & 6 & 8 & 8 \\
\hline Machine-hours, $\mathrm{h} / \mathrm{m}^{2}$ & 1.49 & 0.89 & 0.79 \\
\hline
\end{tabular}

The distribution of respondents who participated in the survey by work experience in the field of construction is presented in Fig. 4. In total 20 respondents participated in the survey. $40 \%$ of the respondents belonged to a group of $1-5$ years of experience, $5 \%$ belonged to a group of 6-10 years of experience, $45 \%$ belonged to a group of 11-20 years of experience, and $10 \%$ of the respondents belonged to a group of 21 and more years of experience. It can be seen that the vast majority of respondents were 11-20 years old with experience in the field of construction. The distribution of the respondents view on the survey question is presented in Fig. 5.

The Fig. 5 shows opinion of 20 experts. 7 questions were given to the each of the experts where every question represented different criteria for the assessment. As the figure shows most of the respondents choose wooden frame module as more favorable survey answer.

After an expert evaluation of the criteria, it was obtained that the construction time, the value of which is $20.5 \%$, is the most important criterion, second most important is the value of the installation of $1 \mathrm{~m}^{2}$, which is $19.8 \%$ (Fig. 6). The quality of performed works (18.4\%), safety of work during construction $(15.3 \%)$, and environmental protection (11.5\%) are in the order of success. The smallest value is the human work of $1 \mathrm{~m}^{2}$ installed (8.6\%) and the working time of machinery for $1 \mathrm{~m}^{2}$ installation $(6.0 \%)$. After an expert evaluation, the coefficient of concordance is 0.843 , which indicates that the expert opinion is evenly distributed and the survey is reliable.

After evaluation of the theoretical criteria, it was obtained that the main criteria is the human work for $1 \mathrm{~m}^{2}$ installed, the value of which is $26.68 \%$, the importance of mechanisms for $1 \mathrm{~m}^{2}$ installed, having a value of $24.86 \%$, is after it (Fig. 7). The construction time is $18.22 \%$, the environmental protection and work safety is $12.5 \%$, and the quality of work performed is $4.94 \%$. The lowest value is $1 \mathrm{~m}^{2}$ installation cost $-0.3 \%$.

After completing the complex criterion evaluation, it was obtained that construction time, the significance of which is $31.63 \%$, is the most important criteria, and the importance of the human work for $1 \mathrm{~m}^{2}$ installed is still important, with a value of $19.39 \%$ (Fig. 8). The following is in order of safety of works during construction work $-16.15 \%$, the duration of machinery working on $1 \mathrm{~m}^{2}$ is $12.55 \%$, and the environmental protection $-12.11 \%$. The minimum value is the quality of work performed $-7.68 \%$ and $1 \mathrm{~m}^{2}$ installation cost $0.5 \%$.

Next, the significance was evaluated of all alternatives using performance-degree comparison. After an expert comparison of the alternatives, the most important alternative was the modular design of the building of wooden frame (A2) with a value of $99.68 \%$, second is the modules with
Table 1

Comparison of selected type of building construction

\section{Results}

Fig. 4

Distribution of respondents according to available work experience in the field of construction 
Fig. 5

Distribution of respondents' opinions according to the submitted questionnaire questions

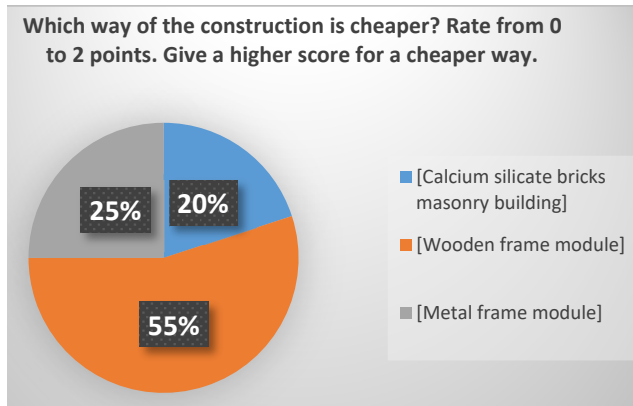

a)

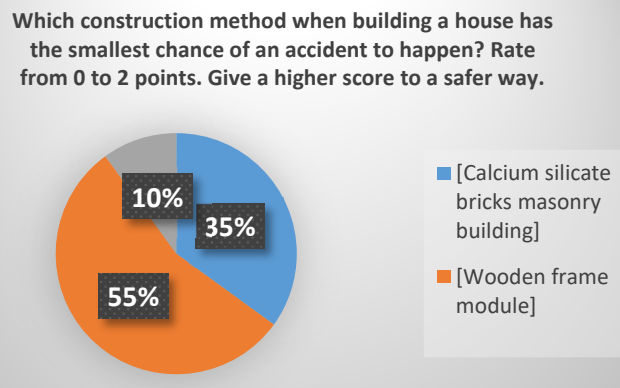

c)

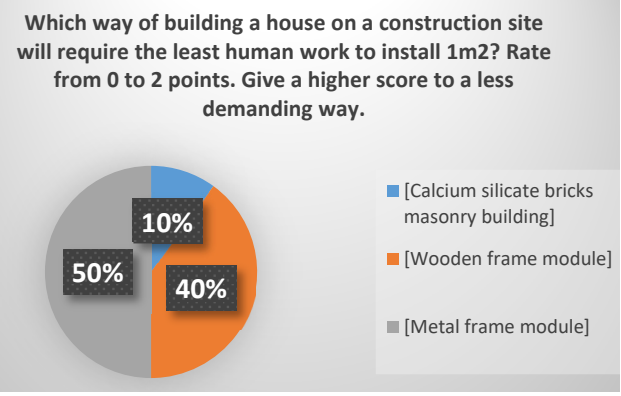

e)

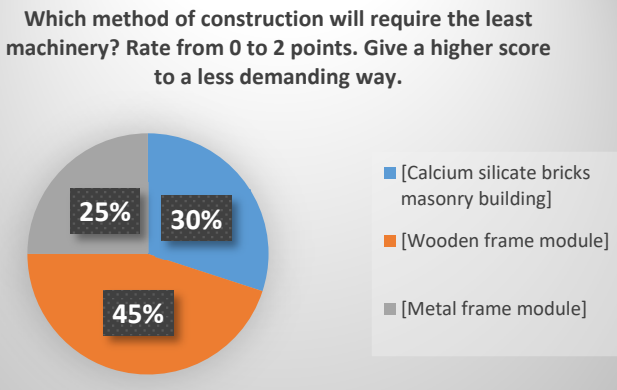

g)

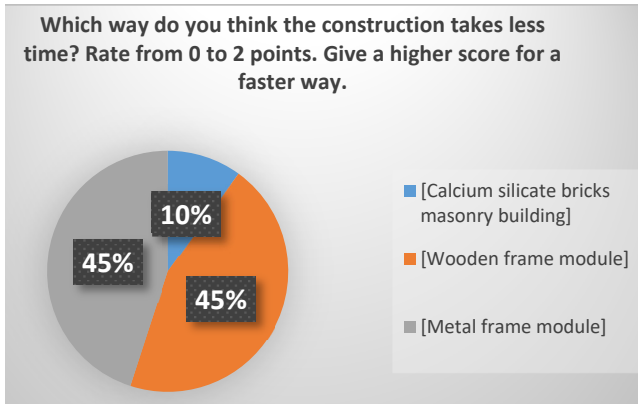

b)

Which way of building a house will leave the least amount of construction waste and air pollution? Rate from 0 to 2 points. Give a higher score to a greener way.

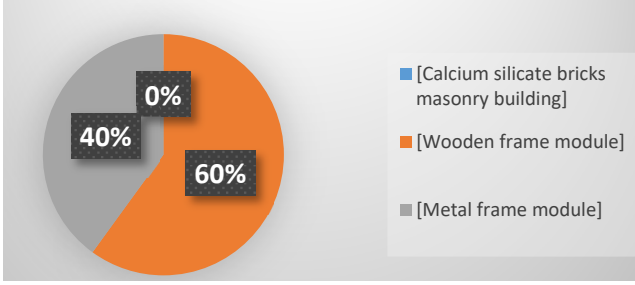

d)

Which way will the house be better built(quality wise)? Rate from 0 to 2 points. Give a higher score a better way.

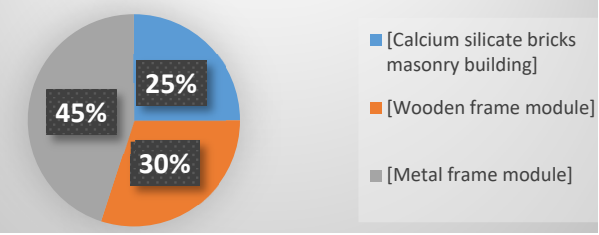

f)

metal frame (A3) of $98.48 \%$ by importance (Fig. 9). The least significant alternative is a traditional calcium silicate bricks masonry building (A1) with a value of $68.76 \%$.

After theoretical comparison of the alternatives the most important alternative is the modular building of the wooden modules (A2) with a value of $99.41 \%$, followed by the metal frame modules (A3) with the value of $97.2 \%$ (Fig. 10). The least significant alternative is a traditional calcium silicate bricks masonry building (A1) with a value of $64.42 \%$. 


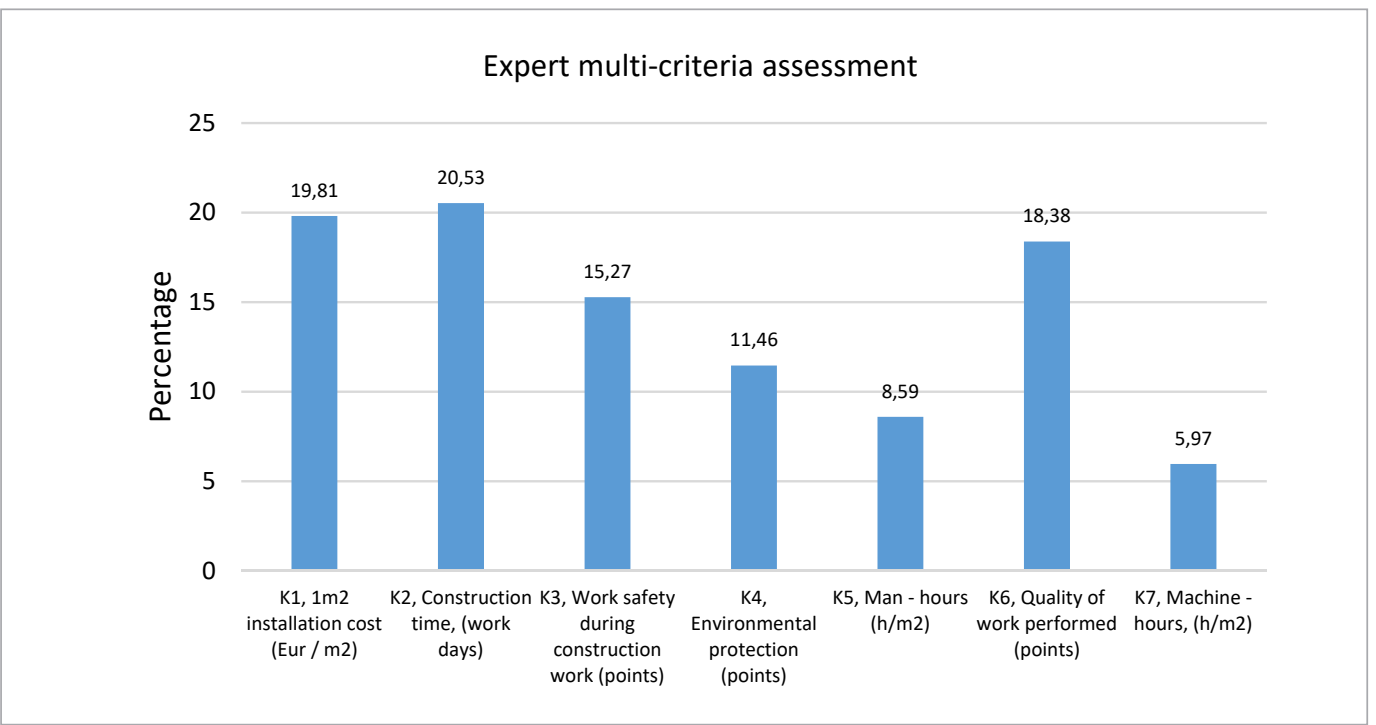

Fig. 6

Results of expert

multi-criteria

assessment

Fig. 7

Results of theoretical multi-criteria assessment
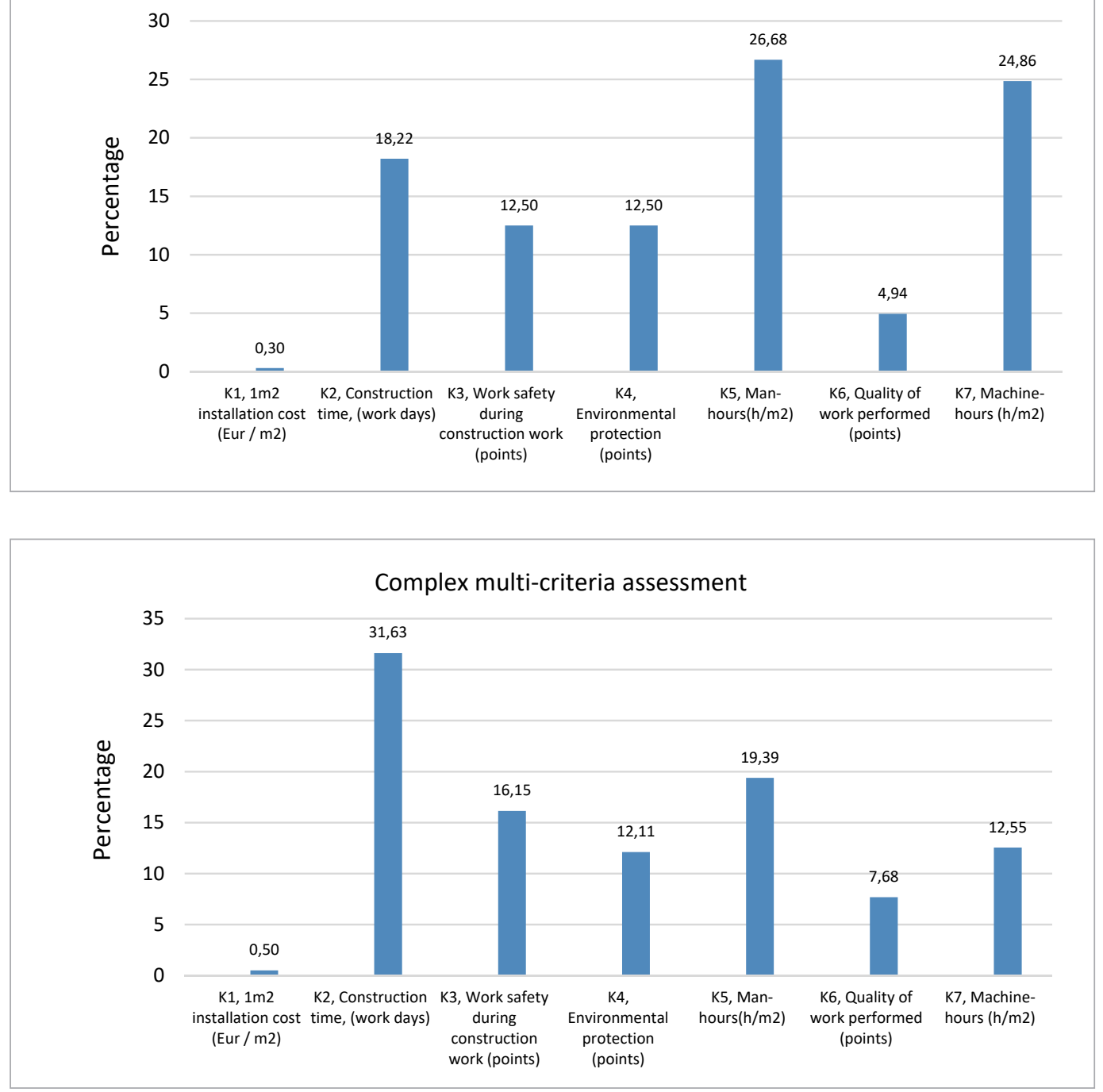

\section{Fig. 8}

Results of complex multi-criteria assessment 


\section{Fig. 9}

Comparison of the degrees of utility of alternatives according to the experimental significance of the schedule

Fig. 10

Comparison of degrees of utility of alternatives according to the complex significance
Conclusions
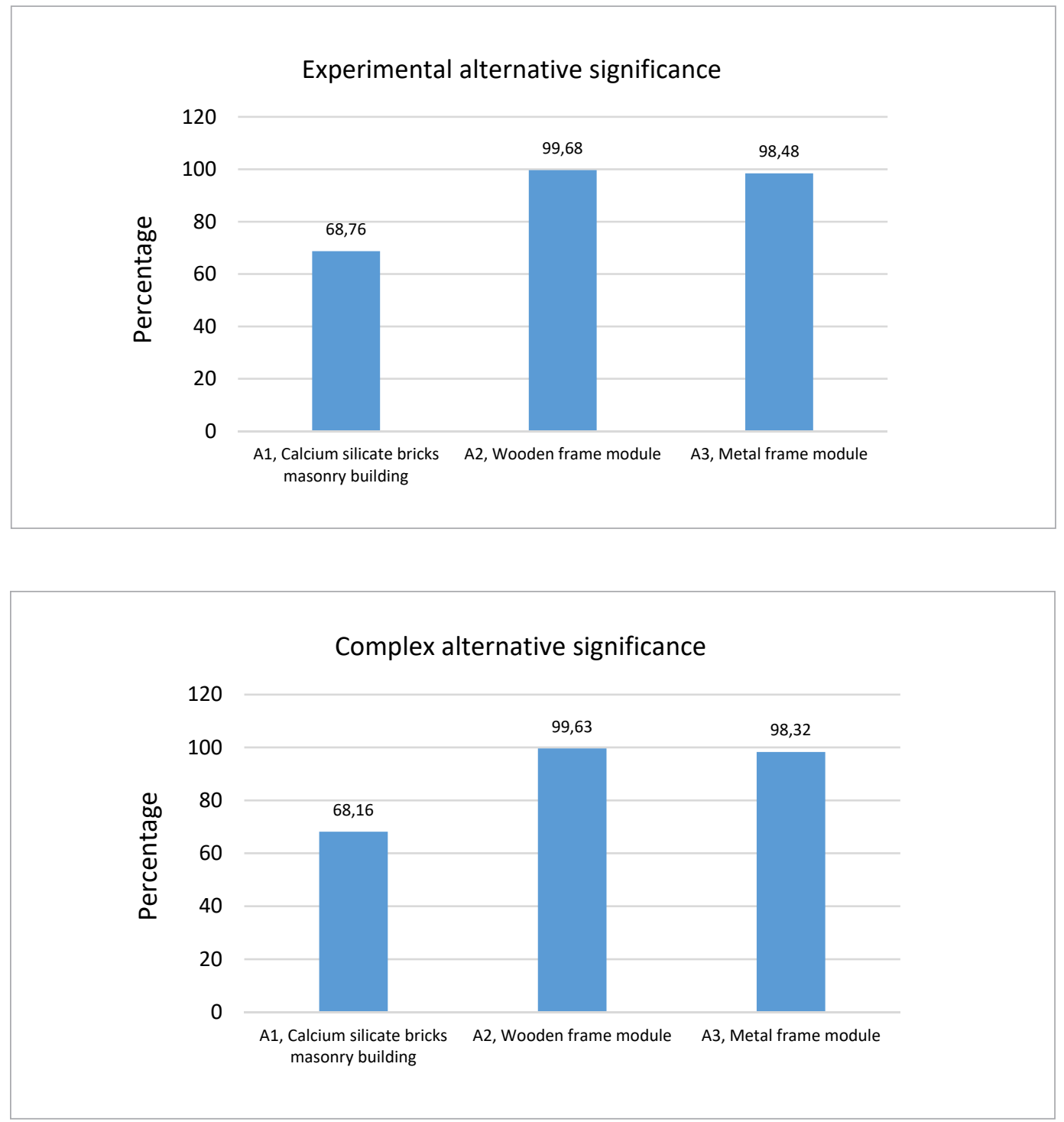

The complex alternative comparison has shown that the most important alternative is the modular building with the wooden frame (A2) with value of $99.63 \%$, followed by the modules of the metal frame modular building (A3), which is $98.32 \%$. The least significant alternative is a traditional calcium silicate bricks masonry building (A1) with a value of $68.16 \%$.

Coefficient of concordance of the survey is 0.843 , which indicates that the expert opinion is evenly distributed and the survey is reliable. Most of the respondents choose wooden frame module as more favorable survey answer

Using complex criteria evaluation, the most important criteria is construction time (K2), the $\angle$ significance of which is $31.63 \%$, followed by the man-hours (K5) with a value of $19.39 \%$. The following is in order of work safety during construction work (K3) - 16.15\%, the machine-hours (K7) is $12.55 \%$, and the environmental protection (K4) - $12.11 \%$. The minimum value is the quality of work performed (K6) $-7.68 \%$ and $1 \mathrm{~m}^{2}$ installation cost (K1) $0.5 \%$.

3 Using complex alternative comparison the most important alternative is the modular 3 building with the wooden frame (A2) with value of $99.63 \%$. 
A. C. Jellen, A. M. Memari. The state-of-the-art application of modular construction to multi-story residential buildings, 1 st residential building design \& construction conference - February 20-21, 2013 at Sands Casino Resort, Bethlehem, 2013; 284-293.

A. Morby. Green light for world's tallest modular tower in Croydon. Construction enquirer, 2017, available at: https://www.constructionenquirer. com/2017/12/04/green-light-for-worlds-tallestmodular-tower-in-croydon/

A. Eagle. Speed to Market: Hospitals tap modular construction to meet building demand, Health facil manage, 2014; 27(5):18-23.

B. Sevenson. Chinese unveil mysterious 3D printed house - Built out of unique material, able to withstand devastating earthquakes, 3Dprint.com, 2015, available at: https://3dprint.com/82322/chinese-3d-modular-homes/

D. Lopez, T. Froese. Analysis of costs and benefits of panelized and modular prefabricated homes, Procedia engineering, 2016; 145:1291-1297. https:// doi.org/10.1016/j.proeng.2016.04.166

E. M. Generalova, V. P. Generalov, A. A. Kuznetsova. Modular buildings in modern construction, Procedia engineering, 2016; 153:167-172. https://doi. org/10.1016/j.proeng.2016.08.098

J. Lee, M. Park, H. Lee, T. Kim, S. Kim, H. Hyun. Workflow dependency approach for modular building construction manufacturing process using dependency structure matrix (DSM), KSCE journal of civil engineering, 2017; 21:1525-1535. https://doi. org/10.1007/s12205-016-1085-1

J. Molavi, D. L. Barral. A Construction procurement method to achieve sustainability in modular construction, Procedia engineering, 2016; 145:13621369. https://doi.org/10.1016/j.proeng.2016.04.201

J. Zhang, Y. Long, S. Lv, Y. Xiang. BIM-enabled modular and industrializes construction in China, Procedia engineering, 2016; 145:1456-1461. https://doi. org/10.1016/j.proeng.2016.04.183

M. Kamali, K. Hewage. Development of performance criteria for sustainability evaluation of mod-

\section{JULIUS ENDZELIS}

\section{Master}

Faculty of Civil Engineering and Architecture

Main research area

Construction technology

\section{Address}

Studentu str. 48, LT-51367 Kaunas, Lithuania Tel. +37037300473

E-mail: julius.endzelis@gmail.com ular versus conventional construction methods, Journal of cleaner production, 2017; 142:3592-3606. https://doi.org/10.1016/j.jclepro.2016.10.108

M. Kamali, K. Hewage. Life cycle performance of modular buildings: A critical review. Renewable and sustainable energy reviews, 2016; 62:1171-1183. https://doi.org/10.1016/j.rser.2016.05.031

M. Larsson, A. Kaiser, U. A. Girhammar. Multi-storey modular manoeuvres - Innovative architectural stacking methodology based on three Swedish timber building systems, Auckland, New Zealand 15-19 July 2012, World conference on timber engineering, 2012; 63-72.

I. Matei. Ten fold and the mobile house of the future, Urbanizehub, 2017, available at: http://urbanizehub.com/ten-fold-mobile-house-future/

O. Mohsen, P. Knytl, B. Abdulaal, J. Olearczyk, M. Al-Hussein. Simulation of modular building construction, Proceedings of the 20018 winter simulation conference, 2008; 2471-2478. https://doi. org/10.1109/WSC.2008.4736356

P. Sharafi, M. Mortazavi, B. Samali, H. Ronagh. Interlocking system for enhancing the integrity of multi-storey modular buildings, Automation in construction, 2018; 85:263-272. https://doi. org/10.1016/j.autcon.2017.10.023

R. E. Smith. Off-site construction implementation resource: Off-site and modular construction explained, National institute of building sciences, 2016; 1-6.

The modular building institute. Improving construction efficiency \& productivity with modular construction, 2010, available at: https://cdn.ymaws.com/www.nibs. org/resource/resmgr/OSCC/OSMC_Explained.pdf

T. Ngo, R. Crawford, P. Mendis. Embodied energy analysis of prefabricated reusable building modules for a multi-residential building, 47th ANZSES annual conference, 2009; 1-10.

Y. Ding, E. Deng, L. Zong, X. M. Dai, N. Y. Chen. Cyclic tests on corrugated steel plate shear walls with openings in modularizes-construction, Journal of constructional steel research, 2017; 138:675-691. https://doi.org/10.1016/j.jcsr.2017.08.019 